Гасанова Г.А. Влияние типа семейного воспитания на развитие эмоциональных нарушений у детей младшего школьного возраста

\title{
ПСИХОЛОГИЯ
}

УДК 159.9

DOI: $10.21779 / 2542-0313-2017-32-4-67-73$

\section{Г.А. Гасанова}

\section{Влияние типа семейного воспитания на развитие эмоциональных нарушений у детей младшего школьного возраста}

Бакинский славянский университет; Азербайджан, AZ1014, г. Баку, ул. Сулеймана Рустама, 33; gulya_psy@mail.ru

В статье раскрываются актуальные проблемы современной семьи, в которой поведение родителей и их взаимоотношения влияют на развитие эмоциональных нарушений у детей. Роль психолога заключается в своевременном выявлении подобных нарушений с целью последующего проведения комплексных мероприятий по коррекции поведения и создания благоприятного психологического климата как в учебном процессе, так и в семьях детей младшего школьного возраста. В экспериментальной части исследования были определены типы семейного воспитания и родительского отношения к детям, выявлено наличие взаимосвязи между типом неправильного воспитания и формированием у детей проблем в эмоциональной сфере (тревожность, агрессия, страх, дезадаптация).

Ключевые слова: агрессия, воспитание, дезадаптащия, диагностика, семья, страх, тревожность, эмочиональные нарушения.

Внутрисемейные отношения и их влияние на эмоциональный мир детей. Семья является важным социальным компонентом, связывающим ребенка с социумом, формирующим необходимые жизненные ценности. Все негативные стороны жизни, возникающие в семье, к примеру, конфликты между супругами отражаются на личности ребенка, приводят к изменениям в его эмоциональной сфере и нарушениям в поведении. Если при авторитарном воспитании родители строго наказывают ребенка за любое непослушание и проявление упрямства, то он, скрывая свой гнев в присутствии родителей, пытается вымещать его на более «слабых» объектах. Попустительское отношение к ребенку, непоследовательность в воспитании, отсутствие должного внимания к нему со стороны родителей также приводят к появлению агрессивных черт. Дети в таких семьях стремятся во что бы то ни стало привлечь к себе внимание взрослого, нередко используя для этого агрессивное поведение.

Похожая причина проявления агрессии наблюдается и у детей, чьи родители не уверены в себе, склонны во всем уступать и потакать ребенку. Помимо привлечения к себе внимания такие дети используют агрессию для того, чтобы добиться от родителей выполнения своих желаний. Наличие дискомфорта и противоречий в душе ребенка, отсутствие в нем некой стабильности и уверенности в себе, внутреннее ощущение некоторой неполноценности - все это может служить причиной агрессивного поведения ребенка младшего школьного возраста. «Анализ семьи является одним из первых шагов в процессе психологической диагностики детей, в которой изучение 
Гасанова Г.А. Влияние типа семейного воспитания на развитие эмоциональных нарушений у детей младшего школьного возраста

социального окружения пересекается с исследованием врожденных индивидуальных особенностей ребенка» [3, с. 16].

Не секрет, что все проблемы детей - это продолжение проблем их родителей. Возможно, что присущие мамам тревожность, способность к сопереживанию и чувство вины приводят к подавлению агрессивности там, где мужчины ее не скрывают. Как было отмечено в работе В. Кагана, «поскольку агрессивность традиционно приписывается мужчинам и служит предметом их гордости, они склонны подчеркивать или преувеличивать ее» [2, с. 26].

Сегодня, в век развития информационных технологий, перед родителями стоит большая ответственность в деле правильного воспитания детей, необходимы знание психологии ребенка, его индивидуально-возрастных особенностей, проблем, возникающтх в школе между ребенком и сверстниками, наличие у них общих представлений о педагогической психологии и т. д. Все это тот минимум сведений, которыми должны располагать родители.

Говоря о степени исследованности проблемы, следует отметить, что психология семьи и воспитания детей явилась предметом исследования российских ученых Н.Н. Посысоевой [4], А.С. Спиваковской [7], в трудах которых нашли отражение проблемы влияния семьи на развитие у детей тревожности, страхов, выявление причин, приводящих к возникновению психологических проблем. Современных исследователей привлекают также вопросы социализации детей с ограниченными возможностями [3; $4 ; 5 ; 6]$.

Несомненный интерес для психологов представила работа азербайджанского исследователя Н.3. Чалябиева [9], посвященная проблемам семьи, в которой содержатся ценные материалы, носящие практический характер, помогающие психологу как в консультативной, так и в диагностической работе с семьями. Вопросы семьи, конфликтов в них, пути их разрешения, особенности психодиагностической, психопрофилактической работы психолога с семьями стали объектом исследования другого азербайджанского психолога Л.М. Гурбановой [1].

Цель данной статьи - рассмотреть характер эмоциональных нарушений у детей младшего школьного возраста в бакинских семьях. Экспериментальная работа была проведена нами в начальных классах школ города Баку, выборка состояла из 227 респондентов (семей с детьми). Были получены интересные результаты при анализе карты наблюдения Д. Стотта в отношении детей [5, с. 57-71].

Формы дезадаптированного поведения (результаты исследования). Были выявлены учащиеся, проявляющие формы дезадаптированного поведения. Родителей этих испытуемых мы решили обследовать по методике Эйдемиллера [10, с. 600-605] и по тесту-опроснику «Родительские отношения» А.Я. Варга и В.В. Столина [6, c. 236 242]. К обследованию были привлечены все взрослые (родители, бабушки, дедушки), участвующие в воспитании ребенка. Помимо диагностического блока мы предполагали подготовить и внедрить программу по коррекции семейных отношений, однако в рамках данной статьи нами была поставлена цель лишь представить результаты диагностического исследования, основные моменты которого даны ниже. По тесту-опроснику родительских отношений А.Я. Варга и В.В. Столина показатели распределились следующим образом (таблица 1). 
Гасанова Г.А. Влияние типа семейного воспитания на развитие эмоциональных нарушений у детей младшего школьного возраста

Таблица 1. Результаты по тесту-опроснику «Родительские отношения» (ОРО) А.Я. Варга и В.В. Столина

\begin{tabular}{|c|c|c|}
\hline \multirow{2}{*}{ Тип родительского отношения } & \multicolumn{2}{|c|}{ Семьи младших школьников (227) } \\
\hline & Семьи девочек & Семьи мальчиков \\
\hline Принятие - отвержение & $32(14,09 \%)$ & $25(11 \%)$ \\
\hline Симбиоз & $30(13,2 \%)$ & $24(10,5 \%)$ \\
\hline Авторитарная гиперсоциализация & $27(11,8 \%)$ & $21(9,2 \%)$ \\
\hline Маленький неудачник & $21(9,2 \%)$ & $18(7,9 \%)$ \\
\hline Кооперация & $9(3,9 \%)$ & $20(8,8 \%)$ \\
\hline Итого & $119(52,19 \%)$ & $108(47,4 \%)$ \\
\hline
\end{tabular}

У младших школьников на первом месте оказался тип родительского отношения «принятие-отвержение». Следует заметить, что при личной беседе с родителями, наблюдая за поведением детей, мы отмечали для себя довольно противоречивое отношение родителей к детям. С одной стороны, симпатия, восприятие его таким, каков он есть, а с другой - досада, злость, признание никчемности, неумение и нежелание приспособиться к жизни. Все это нашло свое подтверждение в тестировании, т. к. самый высокий результат был получен именно по шкале «принятие-отвержение» $32(14,09 \%)$ - семьи девочек, 25 (11\%) - мальчиков и «симбиоз» - 30 (13,2\%) - семьи девочек, 24 (10,5\%) - мальчиков.

Шкала «принятие-отвержение» граничит с двойственным типом воспитания: с одной стороны, ребенка уважают, ценят, одобряют, с другой - считают его неприспособленным. Шкала «симбиоз» отражает межличностную дистанцию в общении с ребенком. Родители, чьи показания были отнесены к данной шкале, ощущали себя с ребенком единым целым, стремились удовлетворить все его потребности, оградить от трудностей и неприятностей жизни, постоянно ощущали тревогу за ребенка. Он казался им маленьким, беззащитным. Для выявления вида семейного воспитания был проведен опрос обоих родителей в полных семьях и всех участвующих в воспитании ребенка в неполных семьях. Использование опросника для родителей «Анализ семейных взаимоотношений» (ACB) Э.Г. Эйдемиллера выявил следующие виды семейного воспитания (таблица 2).

Таблица 2. Типы семейного воспитания «Анализ семейных взаимоотношений» (ACB) Э.Г. Эйдемиллера

\begin{tabular}{|l|c|c|}
\hline \multirow{2}{*}{ Тип семейного воспитания } & \multicolumn{2}{|c|}{ Семьи младших школьников (227) } \\
\cline { 2 - 3 } & Семьи девочек & Семьи мальчиков \\
\hline Потворствующая гиперпротекция (ПГ) & $38(16,7 \%)$ & $23(10,1 \%)$ \\
\hline Доминирующая гиперпротекция (ДГ) & $14(6,1 \%)$ & $28(12,3 \%)$ \\
\hline Повышенная моральная ответственность (ПМО) & $22(9,6 \%)$ & $14(6,1 \%)$ \\
\hline Эмоциональное отвержение (ЭО) & $15(6,6 \%)$ & $20(8,8 \%)$ \\
\hline Неустойчивость стиля воспитания (Н) & $13(5,7 \%)$ & $19(8,3 \%)$ \\
\hline Гипопротекция (Г-) & $9(3,9 \%)$ & $12(5,2 \%)$ \\
\hline \multicolumn{1}{|c|}{ Итого } & $111(48,6 \%)$ & $116(50,8 \%)$ \\
\hline
\end{tabular}


Гасанова Г.А. Влияние типа семейного воспитания на развитие эмоциональных нарушений у детей младшего школьного возраста

На данном этапе исследования потворствующая гиперпротекция заняла первое место среди типов семейного воспитания - 61 семья $(26,8 \%)$. Причем в семьях девочек данный тип представлен чаще, нежели у мальчиков. Ребенок находится в центре внимания семьи, которая стремится к максимальному удовлетворению его потребностей. Данный факт был нами взят на заметку, так как подобный тип воспитания способствует развитию у детей демонстративных черт, граничит с истероидными чертами характера. Если своевременно его не откорректировать, то в подростковом возрасте возникнут более серьёзные проблемы.

На втором месте расположилась доминирующая гиперпротекция - 42 (18,4 \%). Данный тип воспитания, с одной стороны, создает условия для детей, которым родитель уделяет достаточно времени и сил, однако ребенок лишается самостоятельности, что впоследствии может отразиться на формировании личности подростка. В нашем исследовании у родителей была выявлена и повышенная моральная ответственность (особенно это проявилось у мам девочек - 22 (9,6 \%), у мам мальчиков - 14 (6,1%), что также создает определенный дисбаланс в воспитании, так как требования завышены, а внимание снижено. Еще два показателя - эмоциональное отвержение (у семей мальчиков выше - 20 (8,8\%), чем у девочек - 15 (6,6 \%) и неустойчивость стиля воспитания (также у мальчиков выше - 19 (8,3\%), у девочек - 13 (5,7\%) - входят в группу риска, так как в дальнейшем у детей могут формироваться невротические изменения, процессы декомпенсации. И последнюю шкалу, хотя она представлена незначительными показателями, нужно принять к сведению. Гипопротекция (семья девочек - 9 (3,9\%), мальчиков - 12 (5,2 \%) - ситуация, при которой ребенок предоставлен сам себе, родителям не хватает времени заниматься детьми. Если своевременно не устранить данный недостаток в воспитании детей, у подростков это может привести к конфликтным ситуациям с родителями, учителями, эмоциональным нарушениям и т. д.

Как уже было отмечено выше, по результатам методики Д. Стотта для каждого учащегося был определен доминирующий синдром. Самые высокие показатели были выявлены по шкале ТД (тревога по отношению к детям) - 32 (14,09 \%) - у девочек, $23(10,1 \%)$ - у мальчиков; ТВ (тревожность по отношению к взрослым) - 24 (10,5 \%) у девочек, 21 (9,2 \%) - у мальчиков; ЭН (эмоциональное напряжение) - 21 (9,2 \%) - у девочек, $19(8,3 \%)$ - у мальчиков.

Для каждого испытуемого были выявлены расхождения и совпадения в типах нарушений воспитания разных членов семьи. При сопоставлении синдромов дезадаптированного поведения и типа негармоничного семейного воспитания были выявлены следующие особенности. Так, эмоциональное отвержение, потворствующая гиперпротекция, жестокое обращение являются источником развития невротических симптомов, эмоционального напряжения, ухода в себя, враждебного и тревожного отношения к взрослым. Теперь нам предстояло выявить соотнесенность типа семейного воспитания со страхами, тревожностью и агрессией. Диагностика страхов выявила наличие различных видов страхов у 159 респондентов. Выявляя связь между типом семейного воспитания и наличием страхов у младших школьников, мы получили следующие результаты (таблица 3). 
Гасанова Г.А. Влияние типа семейного воспитания на развитие эмоциональных нарушений у детей младшего школьного возраста

Таблица 3. Связь между типом семейного воспитания и страхами у младших школьников

\begin{tabular}{|l|c|c|}
\hline \multirow{2}{*}{ Тип семейного воспитания } & \multicolumn{2}{|c|}{ Страхи } \\
\cline { 2 - 3 } & Девочки (107) & Мальчики (52) \\
\hline Потворствующая гиперпротекция (ПГ) & $36(15,8 \%)$ & $4(1,7 \%)$ \\
\hline Доминирующая гиперпротекция (ДГ) & $14(6,1 \%)$ & $12(5,2 \%)$ \\
\hline Повышенная моральная ответственность (ПМО) & $21(9,2 \%)$ & $8(3,5 \%)$ \\
\hline Эмоциональное отвержение (ЭО) & $15(6,6 \%)$ & $13(5,7 \%)$ \\
\hline Неустойчивость стиля воспитания (Н) & $12(5,2 \%)$ & $9(3,9 \%)$ \\
\hline Гипопротекция (Г-) & $9(3,9 \%)$ & $6(2,6 \%)$ \\
\hline
\end{tabular}

Особо хотелось бы подчеркнуть, что школьные страхи, которые нас интересовали в первую очередь, были выявлены при потворствующей гиперпротекции (ПГ), доминирующей гиперпротекции (ДГ) и повышенной моральной ответственности (ПМО). Выявляя степень соотнесенности между типом семейного воспитания и уровнем тревожности (тест школьной тревожности Филлипса), мы получили следующие результаты (таблица 4).

Таблица 4. Связь между типом семейного воспитания и тревожностью у младших школьников

\begin{tabular}{|l|l|c|c|c|c|c|c|c|}
\hline № & \multicolumn{1}{|c|}{ Вид тревожности } & Кол-во \% & ПГ & ДГ & ПМО & ЭО & Н & Г- \\
\hline 1. & Общая тревожность & $32,4 \%$ & & 16 & 13 & 17 & 11 & 9 \\
\hline 2. & Переживание социального стресса & $14,5 \%$ & 16 & 8 & & 9 & & \\
\hline 3. & Страх самовыражения & $14,9 \%$ & 15 & & 8 & & & \\
\hline 5. & Страх ситуации проверки знаний & $6,1 \%$ & 14 & & & & & \\
\hline 6. & $\begin{array}{l}\text { Проблемы и страхи в отношениях } \\
\text { с учителями }\end{array}$ & $3,9 \%$ & 9 & & & & & \\
\hline & \multicolumn{1}{|c|}{ Итог } & $71,8 \%$ & & & & & & \\
\hline
\end{tabular}

В ходе исследования было отмечено, что к возникновению общей тревожности приводят такие типы воспитания, как:

- эмоциональное отвержение (ЭО) - 17, доминирующая гиперпротекция (ДГ) - 16;

- повышенная моральная ответственность (ПМО) - 13;

- неустойчивость стиля воспитания $(\mathrm{H})-11$;

- гипопротекция $(\Gamma-)-9$.

Всего по данному типу тревожности число учащихся составило 32,4 \%.

Переживание социального стресса:

- потворствующая гиперпротекция (ПГ) - 16;

- эмоциональное отвержение (ЭО) - 9;

- доминирующая гиперпротекция (ДГ) - 8 .

Итого $-14,5 \%$.

Страх самовыражения:

- потворствующая гиперпротекция (ПГ) - 15;

- повышенная моральная ответственность (ПМО) - 8 .

Итого - $14,09 \%$. 
Гасанова Г.А. Влияние типа семейного воспитания на развитие эмоциональных нарушений у детей младшего школьного возраста

Страх ситуации проверки знаний обнаружен при потворствующей гиперпротекции (ПГ) - 14 (6,1\%).

Проблемы и страхи в отношениях с учителями:

- потворствующая гиперпротекция (ПГ) - 9 (3,9\%).

При диагностике наличия агрессии у младших школьников (анкета Е.К. Лютовой и Г.Б. Мониной «Признаки агрессивности») был выявлен высокий показатель у 85 респондентов (37,3\%), из них у девочек - 29 (12,7\%), у мальчиков - 56 (24,6 \%). Была определена связь между типом семейного воспитания и присутствием агрессии у детей данной возрастной группы. Ниже представлены результаты, выявляющие соотнесенность типа семейного воспитания с тремя показателями: страх, тревожность, агрессия.

Таблица 5. Сводная таблица соотношения типа семейного воспитания с показателями: страх, тревожность, агрессия

\begin{tabular}{|l|c|c|c|}
\hline \multicolumn{1}{|c|}{ Тип семейного воспитания } & $\begin{array}{c}\text { Страхи } \\
159(69,8 \%)\end{array}$ & $\begin{array}{c}\text { Тревожность } \\
164(71,9 \%)\end{array}$ & $\begin{array}{c}\text { Агрессия } \\
85(37,16 \%)\end{array}$ \\
\hline Эмоциональное отвержение (ЭО) & $28(12,3 \%)$ & $22(9,6 \%)$ & $22(9,6 \%)$ \\
\hline Неустойчивый стиль воспитания (Н) & $21(9,2 \%)$ & $21(9,2 \%)$ & $18(7,9 \%)$ \\
\hline Доминирующая гиперпротекция (ДГ) & $26(11,4 \%)$ & $24(10,5 \%)$ & $19(8,3 \%)$ \\
\hline Гипопротекция (Г) & $15(6,6 \%)$ & $15(6,6 \%)$ & $12(5,2 \%)$ \\
\hline Потворствующая гиперпротекция (ПГ) & $40(17,6 \%)$ & $49(21,5 \%)$ & $7(3,08 \%)$ \\
\hline $\begin{array}{l}\text { 6. Повышенная моральная ответственность } \\
\text { (ПМО) }\end{array}$ & $29(12,7 \%)$ & $33(14,5 \%)$ & $7(3,08 \%)$ \\
\hline
\end{tabular}

Выводы. Таким образом, на данном этапе исследования нами были выявлены данные, необходимые для дальнейшей работы с эмпирическим материалом, обозначилось наличие проблем у детей данной возрастной группы, что послужило отправным пунктом для разработки коррекционной программы, необходимой для снижения всех показателей, которые вышли за пределы принятых норм.

\section{Литература}

1. Гурбанова Л.М. Психологические проблемы и пути их решения. - Сумгаит: Знание, 2012. - 240 с.

2. Каган В. Искусство жить: Человек в зеркале психотерапии. - М.: Альпина нонфикшн: Смысл, 2010. - 420 с.

3. Кармазина В.Д. Влияние стилей семейного воспитания на эмоциональноличностное развитие детей с нарушением зрения // Педагогическое мастерство и педагогические технологии. - 2015. - № 3 (5). - С. 306-308.

4. Хахалова И.В., Истомина О.В., Юдина В.А. Семейное воспитание детей с отклонениями в развитии // Личность, семья и общество: вопросы педагогики и психологии: сб. ст. по матер. XXII Межд. науч.-практ. конф. Ч. II. - Новосибирск: СибАК, 2012.

5. Батурина О.С. Психология ошибок в семейном воспитании: теоретический анализ проблемы // Фундаментальные исследования. - 2013. - № 11 (Ч. 7). - С. 1497 1504.

6. Кожанова T.M. Роль семьи в социализации детей с ограниченными возможностями здоровья // Современные проблемы науки и образования. - 2013. - № 4 // https://www.science-education.ru/ru/article/view?id=9741. 
7. Спиваковская А.С. Психотерапия: игра, детство, семья.- М.: Апрель-Пресс, Эксмо-Пресс, 2000. - Т. 2. - 464 с.

8. Тэммл Р., Дорки М., Амен В. Тест тревожности / Дерманова И.Б. Диагностика эмоционально-нравственного развития. - СПб.: 2002. - С. 19-28.

9. Чалябиев Н.3. Психология семьи. - Баку: Мутарджим, 2015. - 424 с.

10. Эйдемиллер Э.Г., Юстицкис В.В. Опросник «Анализ семейных взаимоотношений» (АСВ) // Психология и психотерапия семьи. - 3-е изд. - СПб.: Питер, 2001. $652 \mathrm{c}$.

Поступила в редакиџю 28 ноября 2017 г.

UDC 159.9

DOI: $10.21779 / 2542-0313-2017-32-4-67-73$

\section{Influence of the type of family education on the development of emotional disorders in children of primary school age}

\section{G.A. Hasanova}

Baku Slavic University; Azerbaijan; AZ1014, Baku, Suleiman Rustam st., 33; gulya_psy@mail.ru

The article reveals the relevant problems of the modern family, in which behavior and the relationship between parents affect the formation of emotional disorders in children. The role of the psychologist is to timely identify these difficulties, with a view to the subsequent conduct of comprehensive measures to correct behavior and create a favorable psychological climate, both in the educational process and in families of children of primary school age. In the experimental part of the study, the types of family upbringing and parental relation to children were revealed, the presence of the relationship between the type of incorrect education and the formation of emotional problems in children (anxiety, aggression, fear, disadaptation) was determined.

Keywords: aggression, education, disadaptation, diagnosis, family, fear, anxiety, emotional disorders.

Received 28 November, 2017 